\title{
Working with JIT requires a Flexible Approach
}

\author{
D. K. Singh ${ }^{1}$ and Dr. Satyendra Singh ${ }^{2}$ \\ ${ }^{1}$ Division of MPA Engineering, Netaji Subhas Institute of Technology, New Delhi-110078, India \\ ${ }^{2}$ Deptt. of Mechanical Engineering, B. T. Kumaon Institute of Technology, Dwarahat-263653 (Almora) \\ Uttarakhand, India
}

\begin{abstract}
Flexibility in management is essential today to survive in the most changing and turbulent environment, especially in the global changing international trade scenario and competitiveness in the world market. More transparency and a greater sense of participative decision-making at different levels of management decisions are vital. Decisions made with an open mind without any presumptions or constraints help in sustaining conducive atmosphere with respect to encouraging innovation in the organization. Flexibility in manufacturing ensures customization of products, which have maximum customer satisfying capability. JIT is an innovative management philosophy which evolved in Japan. Flexibility in organizational management as well as manufacturing management is essentially required to accelerate the pace of JIT implementation. This is possible because of improved communication and cordial working atmosphere among the people, which helps them to coordinate their activities effectively to achieve their common organizational goal of becoming the best and number one in the market by producing the customized products. This is what JIT asks for. In this paper, an attempt has been made to explore how the two flexibilities are critical for JIT and to what extent they affect its implementation.
\end{abstract}

Keywords: Flexibility, Customization, JIT

\section{Introduction}

The evolution of the global economy has intensified competition and organizations have been driven to offer increased levels of customer service in order to survive. This has led to make them flexible in their way of thinking and managing the affairs. Increased flexibility is, in fact, a path to competitive advantage. It enables the organization in achieving its goals and taking decisions on time in a more successful way. The flexible system of management is very much useful in improving attitude and culture, thereby getting more benefits with less effort. Flexibility has got an in-built mechanism to think of new approaches in managing an organization. It creates a freedom in the work environment and gets the best out of people. A number of empirical studies exist, where researchers have attempted to correlate flexibilities attributes with organizational performance $[1,2,3,4$, $5,6]$. Flexibility allows operations to maintain and improve performance in spite of variety, uncertainty and ignorance [7]. Hayes and Wheelwright [8] were among the first to advocate flexibility as one of the primary dimensions of a competitive strategy for a manufacturing business, along with cost, quality and dependability. Gerwin [9] has considered the contribution of flexibility to improving competitiveness. He suggested that the organizational performance depends upon the organization's ability to match the appropriate type of flexibility coming in its way with the corresponding type of environmental uncertainty confronting the organization. Hence it is more important to determine which dimension of flexibility should be increased to improve the business performance. Schmenner and Tatikonda [10] validated Gerwin's model of manufacturing and found that flexibility related operational capabilities are explicit resources and competencies of the firm and that companies should consider these operational capabilities in their strategic process. Lau [4] identified five elements to produce manufacturing flexibility such as workforce anatomy, communication, interdepartmental relationships, supplier flexibility and technology. In order to produce manufacturing flexibility, flexible manufacturing system (FMS) is the most suitable choice where manufacturing operations are fully automated. Many manufacturing businesses are investing heavily in FMS to compete in markets characterized by mass customization, shortened product life cycles, stringent product specifications, and global supply and distribution [11]. Nilsson and Nordhahl $[12,13]$ have developed a framework for practitioners to follow to enhance flexibility for competitive advantage. His approach is pragmatic and therefore useful as it focuses on a process for analyzing and developing flexibility instead of defining a general classification of different types of flexibility.

\section{Manufacturing Flexibility and JIT}

Productivity of a manufacturing unit is linked to the optimum utilization of its resources-materials, capital, energy, labour, equipment and technology. Manufacturing environment helps in achieving this goal by making the related process smoother and easier. Good manufacturing environment facilitates in the production of customized products offering many advantages including total customer satisfaction. Manufacturing 
environment plays a very important role in the successful implementation of JIT. It offers right kind of production atmosphere needed to produce right product at right time and in right quantity.

Flexibility in manufacturing system is an effective tool for surviving in the new manufacturing environment involving extreme uncertainties, keeping in mind the unpredictable behaviour of the customer and dynamic nature of market. Flexibility in manufacturing system ensures improved product quality and mass customization. Meeting the precise requirements of customers is the ultimate goal of JIT, as they are the end users. The reduction of set up time is crucial for reaching high levels of product flexibility [14, 15]. Reduction in set up times allows increased frequency of set up as well as reducing internal lead times, thereby increasing capacity utilization. The shorter lead time enhances customer response. Also, due to shorter queues in different phases of the processes, results in reduced inventory level. Small batch production is recommended for a JIT system as it reduces work-in-progress (WIP) inventory and increases responsiveness and flexibility.

The recent trend toward JIT management system and the ever increasing pressure to reduce work-inprocess (WIP) inventories while simultaneously increasing quality has forced companies to install flexible manufacturing system (FMS). A flexible manufacturing system (FMS) is defined as a computer-controlled configuration of semi-dependent workstations and material-handling systems designed to efficiently manufacture low-to-medium volumes of various job types [16]. In order to compete in today's dynamic world market, innovative developments in manufacturing technology is an essential requirement. The emergence of flexible manufacturing systems has the ability to bring innovative changes in manufacturing system. But for FMS to be fully operational to its fullest capacity, cutting tools should be judiciously and rightly used, otherwise the system will reduce to inflexible in practice and the objectives of FMS can not be realized. Hence there is a growing need to integrate tool management more thoroughly into system design and planning and control, with increasing automation in manufacturing systems. An overview of tool management approaches has been given by Crama [17]. Manufacturing companies are switching over to cellular manufacturing environment for increased manufacturing flexibilities and are discarding traditional manufacturing methods. Cellular manufacturing is an application of group technology (GT), which allows for small batch production to gain economic advantages similar to mass production while retaining the flexibility of the job shop [18]. It is an innovative approach to ensure variety in the production with additional benefits of reduced material handling, reduced work-in-process (WIP) inventory, reduced setup time and manufacturing lead time, and simplified planning, routing and scheduling activities [19]. Increased global competition, demand for an increased variety of products, reduced product life-cycles and time-to-market are forcing new strategy to adopt. The mass production is being replaced by mass customization of goods and services [20].

\section{Organizational Flexibility and JIT}

JIT is an innovative approach and it is people oriented. The success of JIT depends to a great extent on how the organization responds to changes required to make atmosphere conducive for innovative developments. The degree of centralization, formalization and complexity which are crucial for innovation, play an important role. Rubenstein [21] has stated that innovation process is essentially a people process and that organizational structure, formal decision-making processes, delegation of authority and other formal aspects of a so called well-run company are not necessary conditions for successful technological innovation. World class manufacturers put great stress on team work and people involvement at every stage of operation and activity.

Increasingly, organizations are realizing that organizational flexibility is a source of sustained and competitive advantage. It is the means of implementing an organization's strategy. Because an organizational strategy is always changing in response to changes in the environment, organizational flexibility must be continuously evaluated so as to always stay ahead of competition. Organizational flexibility is one of the important aspects of JIT implementation. A well designed organization with its informal structure and rich culture helps in the speedy implementation of JIT. It is better for an organization to be open and flexible in order to improve work atmosphere and promote togetherness. Healthy work atmosphere induces innovative thinking useful in the development of customized products. Fast decision making in the most conducive and cooperative atmosphere accelerates JIT implementation. JIT can truly make an organization of world class status.

Organizational structure is the formal system of task and authority relationships that control how people coordinate their actions and use resources to achieve organizational goal [22, 23]. For any organization, an appropriate structure is one that facilitates effective responses to problems of coordination and motivation. Choosing the right number of managers and hierarchical levels is important, as it affects decision making, which influences organizational effectiveness. The choice affects communication and motivation. Lesser number of hierarchy leads to increase the motivational effect of manager as he commands more authority and responsibility. Having too many hierarchical levels may hinder communication and lack motivation. As the chain of command lengthens, communication between managers at the top and bottom of the hierarchy takes longer time and it is easier for managers to pass the buck and evade responsibility. The communication problem can also lead to distortion and twisting of information. Information gets distorted as it flows up and down the 
hierarchy through many levels of management [24]. In addition, there is every possibility of manipulation of information while moving up or down the chain by few managers to serve their own interests. Managers can restrict the flow of information to others and allow only the information that serves their own interests. This manipulation of information at different levels may lead to collapse of control in the organization. As a result, the decision-making becomes slower which hurts the performance of organizations that need to respond quickly to customer's needs or the actions of competitors. Also, as the number of levels in the hierarchy increases, the authority and responsibly of managers decrease and this affects the motivation in the organization. Hence it is wiser to restrict the growth of hierarchy. Motivation provides conducive atmosphere for JIT implementation. In fact, it accelerates JIT implementation. In order to implement fast decision, number of levels should be carefully decided and to be kept at minimum. Quality circle, an important component of JIT, is the best example of limited number of persons acting in a group and delivering best for the organization. JIT requires fast decision making so as to accelerate the processes.

Organizational culture is the shared values, principles, traditions and ways of doing things that influence the way organizational members interact with each other and with suppliers, customers and other people outside the organization. In most organizations, these important shared values and practices have evolved over time and determine, in large degree, what employees perceive about their organizational experiences and how they behave in the organization [25, 26, 27]. The important role of human resource management practices in JIT implementation has been stressed upon by many researchers [28, 29]. For successful implementation of either JIT or TQM, a change in corporate culture or a conducive organizational climate has been regarded as one of the major common infrastructural supports [30,31,32,33]. Organizational climate represents the enduring characteristics of a company that is reflected in the attitudes employees show towards the policies, practices and conditions in the work environment. Many researchers have emphasized on the critical role of Japanese culture in the successful implementation of JIT [34, 35, 36]. Japanese culture inspires and encourages the individual to achieve a goal which is within reach, but requires a great deal of discipline and development of a higher level of commitment to achieve. Japanese workers are totally committed to their work and the company. They are loyal, co-operative, and flexible, and willing to work long hours when needed. Workers are offered life-time employment, decisions are taken collectively involving people from top to bottom, and the management keeps a paternalistic approach towards workers and has respect for their workers. This kind of relationship between workers and managers help to build a platform of trust and belief, where one can rely upon another, and may contribute in a supportive way. As workers develop a better sense of ownership of the process, they tend to suggest more for improvement. Employee motivation and cooperation are critical in JIT implementation. Koufteros [37] has found that employee involvement is an essential element for pull production system, which is a major characteristic of a JIT system. Toyota did not stop working on JIT after originating it and continue to improve its implementation. Some of the US companies have adopted the Japanese culture approach to implement JIT and have reported success [38,39]. More and more companies are changing their work atmosphere and getting inspired by the Japanese culture.

Management systems and processes are gradually becoming more participative in nature. The reliance of JIT on a participative management style implies a higher level of employee involvement and empowerment than would have been seen in traditional organization [40]. Flexibility in management is the essential element for survival amidst the turbulence of the changing environment especially, in the global changing international trade scenario and competitiveness in the world market. More transparency and a greater sense of participative decision making at different levels of management are vital. JIT works most effectively in participative atmosphere, as it induces free flow of information among the participating members which is essential for fast and effective decision making. The free flow of information has led to the creation of a borderless world in a big way. The business is being globalized as a consequence of the creation of a borderless world. Japanese work atmosphere is very much participative in nature and so is the principal reason of success of JIT. Participative decision-making at different level of management is helpful in JIT implementation. Organization continues to grow, when it encourages participation and empowerment at every level. Increased participation and empowerment energize greater performance, produce better solutions to problems, and greatly enhance acceptance of decisions. It has been found that group dynamics work to overcome resistance to change, increase commitment to organization, reduce stress levels, and generally make people feel better about themselves and their worlds [41]. Higher level of participation results in increased motivation among the employees. If individuals within the organization see their ideas and efforts contributing to the performance of the business, they will be encouraged still further. On the other hand, if seemingly good ideas are constantly overlooked, this will lead to increased frustration. The Japanese management stresses upon the interaction between management and employee. William Ouchi [42] has focused on the characteristics of an organization. He listed the distinguishing features of Japanese organizations such as lifetime employment, collective decision making, collective responsibility and holistic concern for employees.

JIT is an innovative approach and it is people oriented. Rubenstein [43] has stated that innovation 
process is essentially a people process and that organizational structure, formal decision-making processes, delegation of authority and other formal aspects of a so called well-run company are not necessary conditions for successful technological innovation. World class manufacturers put great stress on team work and people involvement at every stage of operation and activity.

An organization must aspire to move along a path from closed system to open system. While secrecy breeds gossip, mistrust, feelings of being alienated and devalued, organizational transparency ensures the trust and support of all concerned. In view of the complexity of tasks, managers are expected to be open to multiple routes of solving problems. Freedom at the workplace is the independence employees need in order to be motivated and perform to the best of their abilities. Freedom encompasses flexibility on the opportunity to voice their opinions freely and the freedom to exercise their creativity to achieve organizational goals. When people have freedom at work, they ought to give their best. They become emotionally committed to the organization, as opposed to become merely rationally committed. Emotionally committed employees go the extra mile in any assignment, actively seek new challenges and remain engaged with the organization through good times and bad. Freedom at workplace makes employees feel empowered, with a strong sense of ownership and contribution, a freedom to make mistake and to have the power to innovate. It is therefore evident that a democratic organization is a 'progressive' organization and employees who are allowed to follow democracy in the truest sense are happy, engaged and most importantly, productive. Harber [44] has stressed on the need for open management and an ability to accept comments and criticisms from employees, as well as, a need to move away from adversarial roles to a sharing of information and goals for successful implementation of JIT. Decision made with an open mind without any presumptions or constraints eliminate many problems of the organization. Shingo [45], when discussing 'Toyota Production System', also balanced JIT techniques with equal emphasis on respect for humanity to generate sense of ownership and pride of work. One of the important factors which Monden [46] considered essential for effective implementation of JIT included respect for humanity that emphasizes employment involvement, cross training, job design, empowerment and communication.

\section{Combined effect of Organizational and Manufacturing flexibilities}

Organizational management thrusts upon people management. The open working atmosphere and mutual trust and relationship have direct impact on the productivity of the organization. On the other hand, manufacturing management is related to the orderly arrangement of components of manufacturing system, namely workstations, machines, equipments etc. The purpose is to make the plant layout highly effective to reduce manufacturing bottlenecks and ensure smooth operations. An orderly and systematic manufacturing system is helpful in reducing in-process inventory drastically, which is major cause of concern for a manufacturing unit. This in turn directly affects JIT implementation, as JIT does not allow storage of items and always wants them to be in circulation. Organizational management alone can not improve the productivity of an organization as far as a manufacturing unit is concerned. For that it requires to effectively manage the manufacturing components. Upton [1] stated that the flexibility of the plants depends more on people than on technical factor. Using technical solutions, for example use of automated equipments, as a quick fix is not useful. He concluded that manufacturing flexibility involves multiple elements and is not easy to achieve. It is more important to identify the manpower and equipment capabilities to make manufacturing flexible. In order to implement JIT effectively, flexibilities concerning organizational and manufacturing both are equally important. The combined effect results in the reduction of manufacturing lead time and ensures mass customization, which in turn, accelerates JIT implementation.

\section{Conclusions}

JIT is a flexible-based approach so as to remain always relevant. It teaches people how to solve problems, take advantage of opportunity, and learn how to do that better and better over time. JIT can produce miraculous results, if implemented sincerely and honestly. It can change the face of an organization and can place it in the category of best. It can place the organization on the global map. Manufacturing as well as organizational flexibilities both accelerate JIT implementation, but the manufacturing flexibility has more direct impact than organizational flexibility. This is because of the fact that manufacturing flexibility is directly connected with producing customized products which a customer looks for. Increased customer satisfying ability of customized products has more impact on JIT implementation. On the other hand, organizational flexibility helps the organization in taking decisions on time in a more successful way, which is needed to promote manufacturing flexibility and so JIT.

\section{References}

[1]. Upton, D., What really makes factories flexible? Harvard Business Review, July/August, pp. 74-84, 1995a

[2]. Upton, D., Flexibility as process mobility: the management of plant capabilities for quick response manufacturing, Journal of 
Operations Management, Vol. 12,pp. 205-224, 1995b.

[3]. Upton, D., Process range in manufacturing: an empirical study of flexibility, Management Science, Vol. 43, No. 8, pp. 1079-1092, 1997.

[4]. Lau, R. S. M., Critical factors for achieving manufacturing flexibility, International Journal of Operations and Production Management, Vol. 19, No. 3, pp. 328-341, 1999.

[5]. Salvador, F; Rungtusanatham, M; Forza, C and Trentin, A., Mix flexibility and volume flexibility in a build-to-order environment, International Journal of Operations and Production Management, Vol. 27, No. 11, pp. 1173-1191, 2007.

[6]. Zhang, Q; Vonderembse, M. A and Lim, J. S., Manufacturing flexibility: defining and analyzing relationship among competence, capability, and customer satisfaction, Journal of Operations Management, Vol. 21, pp. 173-191, 2003.

[7]. Slack, N., The Manufacturing Advantage, Mercury Business Books, London. 1991.

[8]. Hayes, R and Wheelwright, S., Restoring Our Competitive Edge: Competing Through Manufacturing, Wiley, New York, NY., 1984.

[9]. Gerwin, D., Manufacturing Flexibility: A Strategic Perspective, Management Science, Vol. 39, No. 4, pp. 395-410, 1993.

[10]. Schmenner, R.W and Tatikonda, M.V., Manufacturing process flexibility revisited, International Journal of Operations and Production Management, Vol. 25, No. 12, pp. 1183-1189, 2005.

[11]. Wang, Shengyong; Chew, Song Fob and Lawley, Mark, Guidelines for implementing robust supervisors in flexible manufacturing systems, International Journal of Production Research, Vol. 47, No. 23,1, pp. 6499-6524, December 2009.

[12]. Nilsson, C.H and Nordhahl, H., Making operational flexibility operational-part 1: a framework, Integrated Manufacturing Systems, Vol. 6, No. 1, pp. 5-11, 1995

[13]. Nilsson, C.H and Nordhahl, H., Making operational flexibility operational-part 2: a framework, Integrated Manufacturing Systems, Vol. 6, No. 2, pp. 4-10, 1995.

[14]. Gerwin, D, Do's and Don'ts of Computerized Manufacture, Harvard Business Review, March-April 1982.

[15]. Browne, J; Dubois, D; Rathmil, K; Sethi, S and Steckes, K. E. Classification of Manufacturing Systems, The FMS Magazine, 1984

[16]. Gamila, M.A and Motavalli, S., A modeling technique for loading and scheduling problems in FMS, Robotics and ComputerIntegrated Manufacturing, Vol. 19, No. 1/2, pp. 45-54, 2003.

[17]. Crama, Y and Kluvert, J., Worst case performance of approximation algorithms for tool management problems, Naval Research Logistics, Vol. 46, pp. 445-462, 1999.

[18]. Rajamani, D; Singh, N and Aneja, Y.P., Design of Cellular Manufacturing Systems, International Journal of Production Research, Vol. 34(7), pp. 1917-1928, 1996.

[19]. Akturk, M. S and Turkcan, A., Cellular Manufacturing System design using a holonistic approach, International Journal of Production Research, Vol. 38(10), pp. 2327-2347, 2000.

[20]. Pine, B.J., Mass Customization -The New Frontier in Business Competition, Harvard Business School Press, 1993.

[21]. Rubenstein, A. H., Factors influencing Success at the Project Level, Research Management, Vol. 19(3), pp. 15-20, 1976.

[22]. Barnard, C.I., The Functions of the Executive, Harvard university Press, Cambridge, Mass, 1948.

[23]. Etziomi, A, Modern Organizations, Prentice Hall, Englewood Cliffs, N.J., 1964.

[24]. Katz, D and Kahn, R.L., The Social Psychology of Organizing, Wiley, New York, 1966.

[25]. Shadur, K and Kienzle N.A., The Relationship between Organizational Climate and Employee Perceptions of Involvement, Group and Organization Management, pp. 479- 503, December 1999.

[26]. Hatch, M.J., The Dynamics of Organizational Culture, Academy of Management Review, pp. 657-693, October 1993.

[27]. Smircich, L., Concepts of Culture and Organizational Analysis, Administrative Science Quarterly, p.339, September 1983.

[28]. Spencer, M.S and Guide, V.D., An Exploration of the components of JIT: Case study and Survey results, International Journal of Operations and Production Management, Vol. 15, pp. 72-83, 1995.

[29]. White, R.E; Pearson, J.N and Wilson, J.R., JIT Manufacturing: A survey of implementation in Small and Large U.S. Manufacturers, Management Science, Vol. 45, pp. 1-15, 1999.

[30]. Bright, J and Cooper, C.L., Organizational Culture and the Management of Quality, Journal of Managerial Psychology, Vol. 8, pp. 21-27, 1993.

[31]. Emery, C.R; Summers, T.P and Surak, J.G. The role of Organizational Climate in the implementation of Total Quality Management, Journal of Managerial Issues, Vol. 8, pp. 484-496, 1996.

[32]. Glover, J., Achieving the Organizational Change necessary for Successful TQM, International Journal of Quality and Reliability Management, Vol. 10, pp. 47-64, 1993.

[33]. Morris, L., Organizational Culture and TQM implementation, Training and Development, Vol. 48, pp. 69-71, 1994.

[34]. Manoochehri, G.H., JIT for Small Manufacturers, Journal of Small Business Management, Vol. 26, pp. 22-30, 1988.

[35]. Mussel White, W.C., The Just-in-time Production Challenge, Training and Development Journal, Vol. 41, pp. $27-29,1987$.

[36]. Gettel-Riehl, K and Kleiner, B.H. Lesson from the Japanese Automotive Industry, Industrial Management and Data Systems, U.K; pp. 3-6, 1987.

[37]. Koufteros, X.A; Vonderembse, M.A and Doll, W.J., Developing measures of time-based Manufacturing, Journal of Operations Management, Vol. 16, pp. 21-41, 1998.

[38]. Sakurai, M and Huang, P.Y., Japan's Productivity Growth: A Managerial and Accounting Analysis, Industrial Management, Vol. 26, pp.11-18, 1984.

[39]. Suzuki, K., Work-in-process Management: an illustrated guide to Productivity Improvement, Industrial Management, Vol. 26, pp. 101-110, 1985.

[40]. Lau, R.S.M., A Synergistic Analysis of joint JIT-TQM Implementation, International Journal of Production Research, Vol. 38(9), pp. 2037-2049, 2000.

[41]. McGrath, J.E., Groups; Interaction and Performance, Prentice Hall, Englewood Cliffs, NJ, 1984

[42]. William C, Ouchi., Theory Z: How American Business can meet the Japanese Challenge, Reading, Addison Wesley, Mass, 1981.

[43]. Rubenstein, A. H. Factors influencing Success at the Project Level, Research Management, Vol. 19(3), pp. 15-20, 1976.

[44]. Harber, D; Samson, D. A; Sohal, A. S and Wirth, A., Just-in- time: the issue of implementation, International Journal of Operations and Production Management, Vol. 9, pp. 13-22, 1989.

[45]. Shingo, S., Study of the Toyota Production System from Industrial Engineering point of view, Japan Management Association, Tokyo, 1981.

[46]. Monden, Y., Toyota Production System, Institute of Industrial Engineers, Atlanta, GA, 1983. 